\title{
Rarity of synovitis in polymyalgia rheumatica
}

\author{
V Kyle, J Tudor, E P Wraight, G A Gresham, B L Hazleman
}

\begin{abstract}
The joints of 56 patients with polymyalgia rheumatica were examined for evidence of inflammatory synovitis. $x$ Rays, isotope scans, and thermography supplemented clinical examination. Control sternoclavicular joints were examined at necropsy. Peripheral and axial synovitis were uncommon and the results contrast with the findings of several recent studies.
\end{abstract}

Polymyalgia rheumatica (PMR) has traditionally been viewed as a condition affecting muscles, and many reports have emphasised the rarity of joint involvement ${ }^{1-10}$ on both clinical and radiological assessment. Polymyalgia rheumatica has been defined as 'anarthritic rheumatism'. ${ }^{2}$ Gordon suggested that joint swelling, if present, was due to osteoarthritis. ${ }^{6}$ Dixon stated in 1983 that 'true synovitis' does not occur. ${ }^{11}$ None of these authors reported erosions on $x$ ray.

Recent emphasis has been given to a possible association between synovitis and the muscle symptoms in PMR and it has been suggested that both axial and peripheral synovitis often occur. Coomes and Sharp claimed that muscles were not the source of symptoms, and they reported referred pain 'over the muscle masses' by injecting saline into central ligaments, joints, and soft tissues. ${ }^{12}$ Minor chronic inflammatory infiltration was reported in shoulder and acromioclavicular biopsy specimens in two early series. ${ }^{13} 14$ Bruk described synovial thickening or effusions in two thirds of 80 patients with PMR ${ }^{15} ; 40 \%$ of the sternoclavicular joints were thickened and biopsy of five showed chronic non-specific synovitis. Erosions of the sternoclavicular or sacroiliac joints, or both, were seen in 17 patients. The Mayo clinic reported abnormal isotope scans both before and after treatment, ${ }^{16}$ and in another study sternoclavicular swelling or tenderness was seen in six of 39 patients with PMR. ${ }^{17}$ In addition Paice et al reported sternoclavicular swelling with erosions in 11/25 cases and abnormal isotope scans in $20 / 22,{ }^{18}$ and Chou and Schumacher also reported a patient with sternoclavicular erosions. ${ }^{19}$ An arthroscopic study of the shoulder showed mild synovitis, but only two of five patients had increased tracer uptake in either shoulder or sternoclavicular joints. ${ }^{20}$ Healey emphasised that peripheral synovitis without erosions, affecting especially knee and wrist, occurred in $31 \%$ of 246 patients. 21

There is, therefore, still dispute as to whether axial or peripheral synovitis occurs in PMR, and whether the muscle symptoms are due to axial synovitis. The aim of the prospective study was to look for synovitis in PMR and assess its significance.
Patients and methods

Fifty six patients (42 female, 14 male) with active untreated PMR (17 of whom also had giant cell arteritis (GCA) $)^{22}$ were assessed before treatment and followed up for up to $3 \frac{1}{2}$ years (mean 16 months). The mean age at onset was $70 \cdot 3$ years. All had a negative Rose-Waaler test. Six hundred and fifty six assessments were carried out. Complaints of joint and muscular pain were recorded and the presence and nature of any swelling or tenderness noted. Restriction of movement was recorded. Symptoms were attributed to degenerative disease if bony deformity typical of osteoarthritis was found in the absence of synovial thickening or inflammatory effusions, or plain films showed degenerative changes. Synovitis was diagnosed if there was a history of joint pain and stiffness, with tenderness and synovial thickening on examination and the absence of degenerative changes.

\section{RADIOLOGY}

Plain films and tomograms were carried out in randomly selected patients who had been taking prednisolone for at least two years. Thirty one patients had plain films of the hands, and 22 of the pelvis. Nineteen patients had tomograms of the sternoclavicular joints. In addition, control radiographs were taken of 38 pairs of sternoclavicular joints from patients over 60 years, in whom necropsies had been carried out. These films were all reported by one consultant radiologist.

\section{RADIONUCLIDE SCANS}

Radionuclide scans were carried out on a randomly selected group of 15 patients with active untreated PMR. Nine were carried out with technetium-99m (99m $\mathrm{Tc}$ ) pertechnetate; $370 \mathrm{MBq}$ was injected intravenously and patients' shoulders and knees were scanned 20 minutes after injection. Twelve patients undergoing brain scans, but with no evidence of PMR or joint disease, were used as controls for the pertechnetate group. Six patients had ${ }^{99 m} \mathrm{Tc}$ diphosphonate scans; $550 \mathrm{MBq}$ of isotope was injected and whole body scans carried out four hours later. The degree of tracer uptake was assessed as normal, minimally increased, or significantly increased by a consultant in nuclear medicine.

\section{THERMOGRAPHY}

Thermographs were taken with an AGA thermovision 680 medical system to detect infrared emission from elbows, hands, knees, and feet in 16 patients with active untreated PMR/GCA. Thermography was carried out in a draught free room at $20-21^{\circ} \mathrm{C}$ and recordings were made after a 15 minute equilibration period in the room.

\section{G A Gresham}

Dr Hazleman.

Accepted for publication

31 May 1989$$
\text { significance. }
$$ 
foint abnormalities reported

\begin{tabular}{ll}
\hline foint & $\begin{array}{l}\text { Number } \\
\text { of cases }\end{array}$ \\
\hline Knee & 10 \\
Glenohumeral & 5 \\
Acromioclavicular & 4 \\
Small joints in the & \\
$\quad$ hand & 7 \\
Wrist & 2 \\
Sternoclavicular & 2 \\
Neck & 1 \\
Total & 31 \\
\hline
\end{tabular}
before and after treatment

\section{Results}

CLINICAL

Twenty five patients complained of an episode of joint pain in 31 sites (table). On examination, tenderness was noted in 30 of these sites but swelling in only eight, the knee was most commonly affected (10 cases), followed by small joints in the hand ( 7 cases).

Of these 25 patients, three had joint pain with tenderness or swelling coinciding with activity of PMR. In one of these cases wrist synovitis was diagnosed clinically before and during the onset of PMR. In the other two cases the sternoclavicular and acromioclavicular joints were affected during a flare up in activity of PMR. The joints were tender but not swollen. Radiographs and tomograms of the sternoclavicular joints were normal. The other 22 patients complained of joint pain during the follow up period; their PMR was well controlled in all cases. Eleven had clinical and radiological osteoarthritis, mostly affecting the hand, knee, or cervical spine. Two patients developed transient small knee effusions and two had knee swelling considered to be synovial; no significant radiological degenerative changes were seen. The remaining seven patients had short lived episodes of joint pain and tenderness without swelling, and no firm diagnosis for this could be reached.

Thus three patients had active PMR at the time they developed joint symptoms; wrist synovitis was present clinically in one patient and the acromioclavicular and sternoclavicular pain and tenderness in the other two cases might have been due to synovitis. Four cases of transient knee synovitis occurred, which settled rapidly. This gives a maximum total of five episodes of peripheral synovitis and two of axial synovitis. Although 10 of the remaining complaints related to axial joints, degenerative changes were found in five and all occurred when their PMR was well controlled.

\section{RADIOLOGY}

Degenerative changes were seen in the first carpometacarpal or distal interphalangeal joints of 24 of the 31 hand $x$ rays, and in the hips of 10 of the 22 pelvis $x$ rays. Erosions were seen in two of the 19 sternoclavicular tomograms; roughening of the clavicular surface and irregularity of the medial end of the clavicle were each seen in two patients but without erosion of the sternoclavicular joint.

STERNOCLAVICULAR $x$ RAYS AT NECROPSY

Definite erosions were seen in one case (figure).

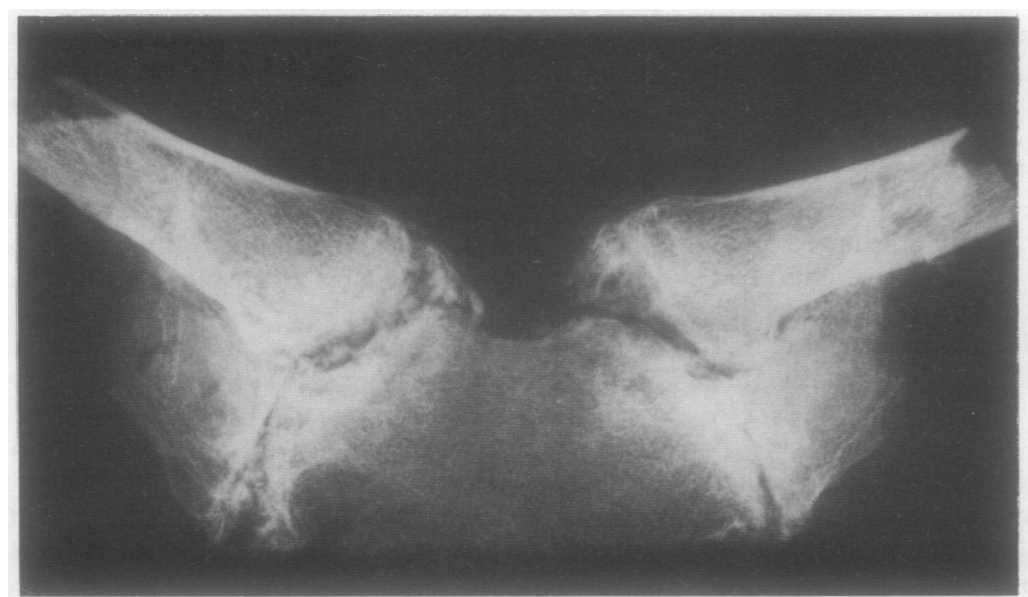

Radiograph at necropsy from a normal control, showing erosions of the sternoclavicular joints.
The patient was an 80 year old man who died from left ventricular failure; there was no history of PMR or joint disease and there was no evidence of these at necropsy.

\section{RADIONUCLIDE SCANS}

Diphosphonate scans in six patients showed increased uptake over the sternoclavicular joints in only one patient.

Comparison of the pertechnetate scans from nine patients with PMR and from 12 controls showed no significant differences between the two groups.

No peripheral synovitis was detected in the 16 patients examined.

\section{Discussion}

Peripheral synovitis was diagnosed clinically in five patients, and in only one case did this occur at the onset of PMR when the disease was active. Neither thermography nor radionuclide scans taken before treatment when PMR was active showed evidence of synovitis. No erosions were seen on plain films of the hands. We have previously shown that thermography is a sensitive method of detecting peripheral synovitis. ${ }^{23}$ Peripheral synovitis was therefore diagnosed in a maximum of $5 / 56(9 \%)$ patients and does not appear to be a common or significant feature of PMR.

Axial joint abnormalities which coincided with active PMR were found in the sternoclavicular joints in one case and in the acromioclavicular joint in another and were considered clinically to be due to synovitis. Another five cases of axial joint pain with no evidence of degenerative disease occurred while the PMR was well controlled. It is clearly difficult to make a definite diagnosis of synovitis in axial joints; fluid is rarely obtained and synovial thickening not usually found. Even if all the above episodes are classed as synovitis, a maximum of $7 / 56(13 \%)$ patients were affected on $1 \%$ of all assessments. Only $2 / 56(4 \%)$ of patients had axial synovitis coinciding with proximal muscle symptoms, sternoclavicular erosions were seen in only $2 / 19(11 \%)$ of the tomograms performed; the patient who had sternoclavicular synovitis clinically had a normal tomogram. The necropsy showed that sternoclavicular erosions can occur in normal controls. Plain films of the pelvis did not show erosions of the sacroiliac joints or symphysis pubis (as reported by Bruk ${ }^{15}$ ), and only one of the 15 radionuclide scans $(7 \%)$ showed increased uptake (over the sternoclavicular joints).

It is difficult to attribute the profound muscle pain and stiffness experienced by these patients to synovitis of the shoulder sternoclavicular joints or hips and lumbar spine when most patients showed no signs of joint inflammation clinically, radiographically, or on isotope scans. In particular, reports of the development of sternoclavicular erosions in the absence of pain or tenderness over the joints are difficult to explain.

Degenerative disease was common both clinically and on radiographs, as might be expected in an elderly population.

There are several factors which may contribute to the discrepancies between our findings and those of other studies. The diagnostic criteria for PMR vary-many patients in the Mayo clinic study had upper limb symptoms alone ${ }^{16}$; Bruk included patients with joint or soft tissue swelling 
and a normal erythrocyte sedimentation rate. ${ }^{15}$ Both these papers have stated that axial or peripheral synovitis are of importance or even causal in PMR, yet their patients do not conform to accepted diagnostic criteria.

A further problem arises over the definition of synovitis, which has been equated with arthralgia in some studies. Although Healey stated that PMR should be reclassified as 'benign seronegative rheumatoid arthritis' because he felt that the first five American Rheumatism Association (ARA) criteria were often fulfilled, he went on to suggest that the ARA criteria were too broad to specify rheumatoid arthritis. ${ }^{21}$

Factors relating to specific assessment techniques have contributed to the controversy. Many found radiographs or isotope scans difficult to interpret because of coexisting degenerative disease. $^{6} 151618$ There was a poor correlation between clinical and scan abnormalities in both the Mayo clinic studies, ${ }^{1624}$ and uptake in the sternoclavicular joints was not increased. Despite this, and the difficulties they found in the interpretation because of degenerative disease, they felt central arthritis caused PMR. Only one study reports sternoclavicular erosions and increased uptake in the sternoclavicular joints on $\operatorname{scan}^{18}$; however, the patients were atypically young (mean age 59 years) and scan abnormalities also surprisingly affected the elbow and hand. Control scans were not carried out. It seems possible that some studies have overinterpreted the radiography or isotope scan results, and that patients with rheumatoid and degenerative arthritis or other disease might have been included in some series. There is no good histological evidence of synovitis - one study with standard diagnostic criteria for PMR reported mild changes on shoulder arthroscopy. ${ }^{20}$

Peripheral synovitis, therefore, appears uncommon in PMR; when it occurs it is transient, non-erosive, and non-deforming. There is no convincing evidence that axial synovitis occurs often in PMR or that it causes the marked muscle symptoms of pain, stiffness, and sometimes tenderness. The case put forward by others rests on dubious reports of clinical synovitis, radiological abnormalities, some of which have been unconfirmed or due to coincidental degenerative disease, reports of mild histological synovitis, and two reports of differing scan abnormalities. There is no resemblance to the synovitis of rheumatoid arthritis; PMR does not cause juxta-articular osteoporosis and erosions; flexion contractures and tendon rupture are not seen. Rheumatoid factors cannot be detected in serum or synovial fluid, and the dramatic, rapid, and usually permanent response to small doses of corticosteroids is also quite unlike the response in rheumatoid arthritis.
The findings of arteritis in skeletal muscle are isolated, ${ }^{25}{ }^{26}$ but it remains possible that arteritis in muscles causes symptoms of PMR. Nonspecific abnormalities have also been shown by muscle biopsy. ${ }^{27} 28$ Further work needs to be carried out on muscle.

1 Cooke W T, Cloake P C P, Govan A D T, Colbeck J. Temporal arteritis: a generalised vascular disease. $Q \mathcal{F}$ Med 1946; 15: 47-75.

2 Bagratuni L. A rheumatoid syndrome occurring in the elderly. Ann Rheum Dis 1953; 12: 98-104.

3 Kersley G D. Anarthritic rheumatoid disease. Lancet 1956; ii: 840 .

4 Barber H S. Myalgic syndrome with constitutional effects. Polymyalgia rheumatica. Ann Rheum Dis 1957; 16: 230-7. 5 Paulley J W, Hughes J P. Giant cell arteritis, or arteritis of the aged. Br Med $\mathcal{F}$ 1960; ii: 1562-7.

6 Gordon I. Polymyalgia rheumatica. A clinical study of 21 cases. $Q 7$ Med 1960; 29: 473-88.

7 Dixon A St J, Beardwell C, Kay A, Wanka J, Wong Y T. Polymyalgia rheumatica and temporal arteritis. Ann Rheum Dis 1966; 25: 203-8.

8 Hamilton C R, Shelley W M, Tumulty P A. Giant cell arteritis: including temporal arteritis and polymyalgia rheumatica. Medicine (Baltimore) 1971; 50: 1-27

9 Bengtsson B A, Malmvall B E. Giant cell arteritis. Acta Med Scand 1982; (suppl): 658

10 Sorensen P S, Lorenzen I. Giant cell arteritis, temporal arteritis and polymyalgia rheumatica. Acta Med Scand 1977; 201: 207-13.

11 Dixon A St J. Polymyalgia rheumatica. In: Hawkins C, Currey H L F, eds. Reports on rheumatic diseases. No 86. London: Arthritis and Rheumatism Council, 1983.

12 Coomes E N, Sharp J. Polymyalgia rheumatica. A misnomer? Lancet 1961; ii: $1328-31$.

13 Gordon I, Rennie A M, Branwood A W. Polymyalgia rheumatica. Biopsy studies. Ann Rheum Dis 1964; 23: r47-54

14 Andrews $T$ M. Polymyalgia rheumatica. A biopsy and followup study. Ann Rheum Dis 1965; 24: 432-8.

5 Bruk M I. Articular and vascular manifestations of polymyalgia rheumatica. Ann Rheum Dis 1967; 26: 103-13.

6 O'Duffy J D, Wahner H W, Hunder G G. Joint imaging in polymyalgia rheumatica. Mayo Clin Proc 1976; 51: 519-24.

17 Miller L D, Stevens M B. Skeletal manifestations of polymyalgia rheumatica. JAMA 1978; 240: 27-9.

18 Paice E W, Wright F W, Hill A G S. Sternoclavicular erosions in polymyalgia rheumatica. Ann Rheum Dis 1983; 42: $379-83$.

19 Chou C T, Schumacher H R. Clinical and pathological studies of synovitis in polymyalgia rheumatica. Arthritis studies of synovitis in polyt

20 Douglas W A C, Martin B A, Morris J H. Polymyalgia rheumatica: an arthroscopic study of the shoulder joint. Ann Rheum Dis 1983; 42: 311-6.

21 Healey L A. Polymyalgia rheumatica and the ARA criteria for rheumatoid arthritis. Arthritis Rheum 1983; 26: 1417-8.

22 Jones J G, Hazleman B L. Prognosis and management of polymyalgia rheumatica. Ann Rheum Dis 1981; 40: 1-5.

23 De Silva M, Kyle V, Hazleman B L, Salisbury R, Page Thomas $P$, W raight $P$. Assessment of inflammation in the theumatoid knee joint: correlation between clinical, radioisotopic and thermographic methods. Ann Rheum Dis 1986; isotopic and $277-80$.

24 O'Duffy J D, Hunder G G, Wahner H W. A follow-up study of polymyalgia rheumatica: evidence of chronic axial synovitis. F Rheumatol 1980; 7: 685-93.

25 Russell R W R. Muscular involvement in giant cell arteritis. Ann Rheum Dis 1962; 21: 171-3.

26 Bussiere J L, Dubost J J, Janinmercier A, Amouroux J, Rampon S. Arterite temporale avec angeite necrosante musculaire. Ann Med Interne (Paris) 1984; 135: 523-5.

27 Brooke M H, Kaplan H. Muscle pathology in rheumatoid arthritis, polymyalgia rheumatica and polymyositis. arthritis, polymyalgia rheumatica a

28 Fassbender R, Simmking-Annefeld $M$. Ultrastructural examination of the skeletal muscles in polymyalgia rheumatica. F Pathol 1982; 137: 181-92. 